\title{
Gestão da qualidade como estratégia para melhorias no rendimento operacional de indústrias queijeiras
}

\author{
Quality management as a strategy for improvement in the operating \\ income of cheese-making industries
}

\section{Resumo}

\author{
Luiz Célio Souza Rocha ${ }^{\mathrm{I}}$ \\ Jéssica Fernandes Carvalhais ${ }^{2}$ \\ Maurilio Lopes Martins ${ }^{3}$
}

\begin{abstract}
Quando se analisa o setor de lácteos brasileiro, constata-se que muitas empresas ainda estão distantes da implementação de estratégias que possibilitem o alcance de diferenciais competitivos. O presente trabalho buscou quantificar as perdas operacionais em uma fábrica de queijo localizada no Município de Rio Pomba/MG considerando o não uso de um programa de garantia da qualidade que refletisse na melhoria da matéria-prima. Como resultado, obteve-se que o rendimento foi significativamente afetado pelo tempo de armazenamento. Por fim, conclui-se que a implementação da gestão da qualidade na indústria queijeira analisada melhoraria seu desempenho operacional e econômico.
\end{abstract}

Palavras-chave: Gestão da Qualidade, Indústrias Queijeiras, Rendimento Operacional.

\begin{abstract}
When analyzing the Brazilian dairy sector, many companies are far from implementation of strategies that enable to reach competitive differentials. The present work aimed to quantify operational losses in a cheese factory located in Rio Pomba city considering the no use of a quality assurance program that would improve the raw material. As result, was found that the productivity was significantly affected by the time of storage, because of the increasing of bacterial counts, causing substantial financial losses. Lastly, this work concludes that the implementation of quality management in the cheese industry analyzed would improve its operational and economic performance.
\end{abstract}

Keyword: Quality Management, Cheese Industries, Operational Productivity.

\footnotetext{
1 luizrochamg@hotmail.com, Brasil. Professor do Instituto Federal do Sul de Minas Gerais - IFSULDEMINAS. Doutorando em Engenharia de Produção na Universidade Federal de Itajubá - UNIFEI. Rod. Machado-Paraguaçu, km 3, Santo Antônio, CEP: 37750-000 - Machado, MG - Brasil.

2 jessicacsa@hotmail.com, Brasil. Doutoranda em Ciência e Tecnologia de Alimentos na Universidade Federal de Viçosa UFV. Av. PH Rollfs, s/n, Campus Universitário, CEP: 36570-000 - Viçosa, MG - Brasil.

3 jadersouza@talentus4.com.br, Brasil. Professor do Instituto Federal do Sudeste de Minas Gerais - IF SUDESTE MG. Doutor em Microbiologia Agrícola pela Universidade Federal de Viçosa - UFV. Av. Dr. José Sebastião da Paixão, s/n, Lindo Vale, CEP: 36180-000 - Rio Pomba, MG - Brasil.
} 


\section{Introdução}

Os estudiosos da Administração, ao longo de sua trajetória, têm-se dedicado à busca de instrumentos que possibilitem melhorar o desempenho das organizações, transformando-as em unidades mais eficientes e produtivas (ETZIONI, I98I). Para o alcance de tais objetivos, faz-se necessário analisar o atual contexto mercadológico cada vez mais competitivo e dinâmico. Fenômenos como globalização e desregulamentação do mercado, além de algumas estratégias utilizadas pelas organizações, na tentativa de se tornarem mais competitivas, como as fusões, aquisições e privatizações, tornam-se cada vez mais rotineiros, demonstrando as constantes mudanças e o aumento da complexidade do ambiente empresarial.

Nota-se que, na busca de aumento do grau de competitividade, grande parte das empresas brasileiras tem feito esforços no sentido de modernizarem sua capacidade gerencial através do desenvolvimento de recursos humanos e aperfeiçoamento da administração da produção, marketing, vendas e custos, além de buscar o aprimoramento da qualidade através da introdução de procedimentos de controle de qualidade e adoção de sistemas de gerência da qualidade total (CAMPOS, I997).

Porém, quando se analisa o setor de lácteos brasileiro, constata-se que muitas empresas ainda estão distantes da implementação de estratégias que possibilitem o alcance de diferenciais competitivos. Esta realidade é constatável, porque, apesar de a produção de leite estar distribuída por todo o país, a heterogeneidade do processo produtivo é marcante (CARVALHO et al., 20O7). Segundo Milinski et al. (2008), a produção de leite no Brasil é composta pelo grupo dos produtores empresariais especializados, encontrados em pequeno número, mas com grande produtividade e qualidade e pelo grupo dos pequenos produtores, pouco especializados que vendem pequenos volumes de leite, de baixo custo e qualidade e que respondem por parte significativa do mercado. Para esses pequenos produtores, a pecuária leiteira tem um importante papel social, uma vez que a atividade permite fixar o homem no campo, reduzindo as pressões sociais nas áreas urbanas (MILINSKI et al., 2008).

Além da importância social da pecuária leiteira, tem-se a importância econômica dessa atividade. Carvalho (2OIO) cita que a participação dos laticínios no faturamento 
total da indústria de alimentos é de, aproximadamente, IO\%, valor bastante significativo quando se analisam os R \$29I,6 bilhões movimentados pelo setor de alimentos em 2009.

Para continuar em crescimento, o setor laticinista precisa atender às atuais tendências do mercado global por alimentos de qualidade, produzidos de forma social e ambientalmente sustentáveis. Ao perseguir a abertura de mercados externos é necessário repensar estratégias competitivas e tratar os aspectos de qualidade na produção. Neste contexto, para Carvalho et al. (2OOz), a Instrução Normativa n ${ }^{\circ} 5^{I}$ (IN 5I) representou uma das mudanças mais significativas do setor em prol da qualidade dos produtos, uma vez que esta legislação estipula valores mais rigorosos para os parâmetros de qualidade do leite.

Tomando-se como base a possibilidade de ganhos de rendimento na produção e redução de custos com a implementação de programas de garantia da qualidade (SPIEGEL et al., 2003), o presente trabalho buscou quantificar as possíveis perdas operacionais em uma fábrica de queijo localizada no Município de Rio Pomba/MG considerando o não uso de um programa de garantia da qualidade que refletisse na melhoria da matéria-prima.

\section{Gestão da Qualidade}

Vários autores se propuseram a conceituar qualidade, não havendo consenso total. Juran e Gryna Jr. (I980) definem qualidade como uma medida da adequação ao uso, considerando que para um produto ter qualidade ele precisaria ter um bom projeto, ser produzido em conformidade com esse projeto, ser seguro para a empresa e o cliente, ter alta confiabilidade em uso e rápido reparo em caso de quebra. Para Crosby (1979), qualidade é a conformidade do produto às suas especificações. Deming (I990) cita que qualidade é tudo aquilo que melhora o produto do ponto de vista do cliente. E, Ishikawa (I985) afirma que qualidade é desenvolver, projetar, produzir e comercializar um produto que é mais econômico, mais útil e sempre satisfatório para o consumidor.

A preocupação com a qualidade não é recente, pois, remonta aos primórdios da civilização onde, nas relações de troca, os consumidores sempre tiveram o cuidado de inspecionar os bens e serviços (LONGO, 1995). Para Garvin (20O2), a evolução dos programas de garantia da qualidade pode ser dividida em quatro "eras da qualidade": da 
inspeção; do controle estatístico da qualidade; da garantia da qualidade; e da administração estratégica da qualidade.

A era da inspeção tem início juntamente com a produção em larga escala onde o intercambiamento das peças na linha de montagem passou a ser considerado fundamental tornando-se necessário o desenvolvimento de uma série de gabaritos e acessórios baseados em um modelo padrão das peças que eram utilizados no alinhamento das ferramentas das máquinas de corte e na inspeção final. Na década de I920, quando a inspeção da qualidade assumiu oficialmente o papel de uma função independente dentro da empresa, seu trabalho consistia em selecionar as técnicas de medição mais adequadas, realizar verificações dimensionais com o uso de ferramentas específicas e decidir entre o uso de amostras aleatórias (sem nenhuma base estatística) e a inspeção de todas a unidades produzidas. As peças com defeito encontradas eram remetidas à produção para serem retrabalhadas ou descartadas evitando, assim, que estas chegassem ao consumidor final (GARVIN, 20O2).

Com o aumento das quantidades e complexidade dos produtos fabricados novas ferramentas precisaram ser desenvolvidas para um controle eficiente da produção. Com isso, a Bell Telephone Laboratories reuniu, no final da década de r920, um grupo de engenheiros e estatísticos, com destaque para W. A. Shewhart, com o objetivo de desenvolver e adaptar ferramentas estatísticas para uso no controle da qualidade. Esse grupo estabeleceu os fundamentos da era do controle estatístico da qualidade (ARNOLD; GÖB, 2005). Ao reconhecer a variabilidade como um atributo normal dos processos produtivos, a grande questão para os inspetores passava a ser reconhecer quando a variabilidade estava fora dos limites considerados normais. Assim, as amostras de peças dos processos controlados eram retiradas e inspecionadas com uma frequência predeterminada. Sempre que os resultados das medidas estivessem fora dos limites de controle, seria o indício de que algo de anormal estaria acontecendo, justificando a interrupção do processo produtivo e a inspeção das peças produzidas. Shewhart desenvolveu, além do Controle Estatístico de Processo (CEP), o ciclo PDCA (Plan, Do, Check, Act) que mais tarde foi disseminado por W. E. Deming.

As décadas de I940 e I950 foram marcadas pelo desenvolvimento do referencial teórico que daria origem à era da garantia da qualidade. Foram desenvolvidas novas 
abordagens como: custos da qualidade (cost of quality - COQ) de Joseph Juran; a do zero defeito, de Phillip Crosby; e a do controle total da qualidade (total quality control - TQC). A possibilidade de quantificar os custos de prevenção e de defeitos, aliada à expansão da prevenção para as atividades de projeto de produto e processo, escolha de fornecedores e treinamento e motivação dos funcionários, caracterizam este período (GARVIN, 2002). Embora os diversos autores da era da garantia da qualidade fossem norte-americanos e atuassem nos Estados Unidos, a utilização efetiva das muitas ferramentas propostas aconteceu no Japão. Após a Segunda Guerra Mundial, o Japão se encontrava totalmente destruído e precisando iniciar seu processo de reconstrução. W. E. Deming foi convidado pela Japanese Union of Scientists and Engineers (JUSE) para treinar os principais dirigentes industriais japoneses sobre controle estatístico de processo e sobre gestão da qualidade (LONGO, I996).

A era da administração estratégica da qualidade tem como sua principal característica a relação dos programas de garantia da qualidade com a consecução dos objetivos estratégicos da empresa. Portanto, qualidade não exige apenas um bom desempenho da função produção da empresa e sim de todas as suas funções principais, como produção, marketing e desenvolvimento de produtos (GARVIN, 2002).

Cerqueira (2007) apresenta uma figura que, de certa forma, encaixa-se com o exposto por Garvin (2002). Assim, a Figura I apresenta a evolução da gestão da qualidade, partindo-se de uma vertente focada no produto (era da inspeção) para uma vertente focada no negócio (era da administração estratégica da qualidade). 
Figura r. Evolução da Gestão da Qualidade

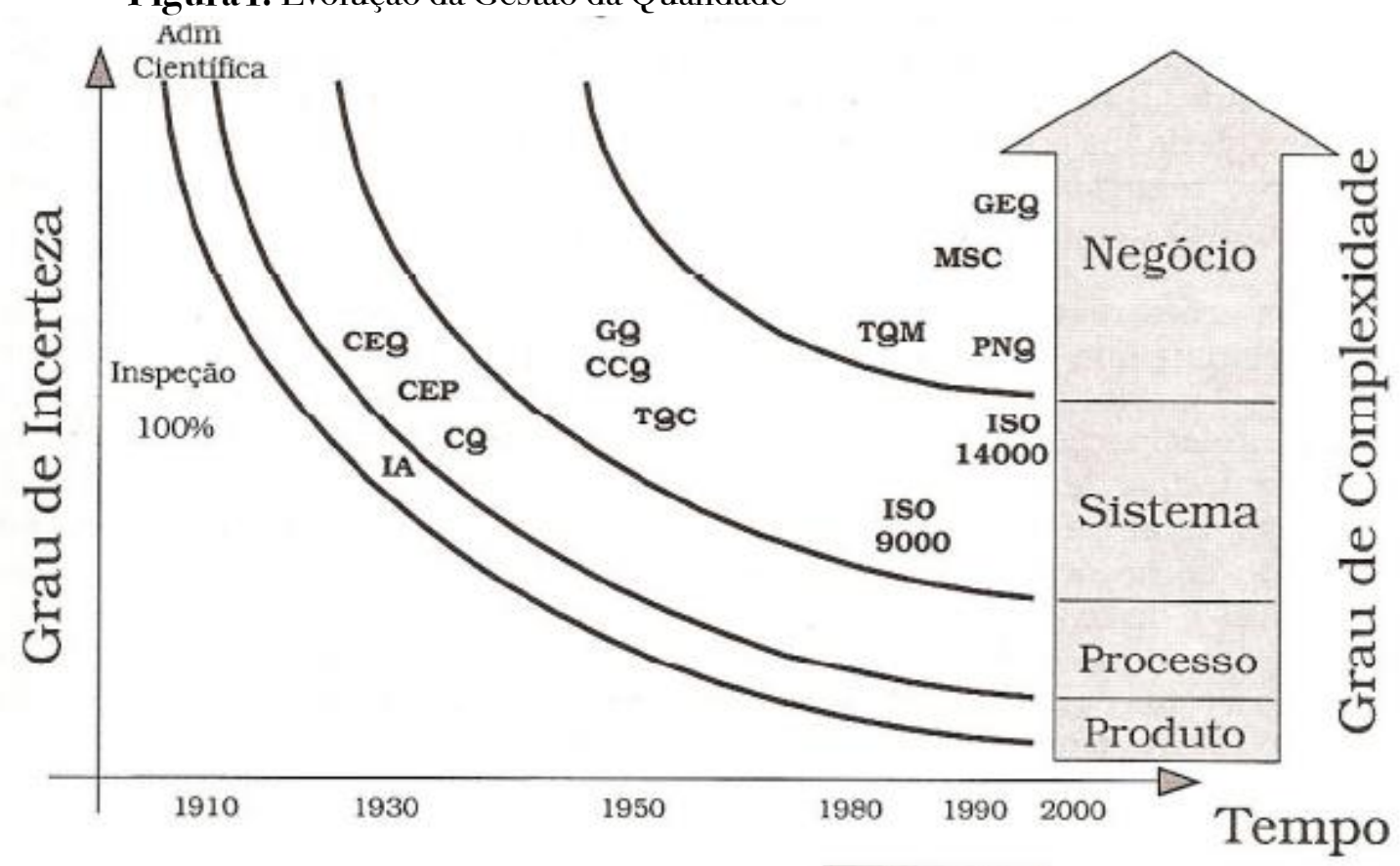

PREDITIVO

PREVENTIVO

\section{REATIVO}

CQ - Controle da Qualidade

CEQ - Controle Ectatístico da Qualidade

CEP - Controle Estatístico do Processo

CCQ - Círculos de Controle da Qualidade

GQ - Garantia da Qualidade

IA - Inspeção por Amostragem

\section{Estilos de}

Gestão

Fonte: Cerqueira (2007, p. I5).

MSC - Medição da Satisfação do Cliente
TQC - Tutul Quulity Control
TQM - Total Quality Management
GEQ - Gestão Estratégica da Qualidade
PNQ - Prêmio Nacional da Qualidade

\section{Gestão da Qualidade na Indústria de Alimentos e Laticínios}

Quando se analisa a indústria de alimentos há duas características marcantes que condicionam sua gestão da qualidade. A primeira está ligada aos parâmetros e exigências que o consumidor não consegue identificar diretamente, mas que estão definidas nos requisitos legais aplicáveis à sanidade do produto em geral. A segunda refere-se às propriedades sensoriais e de apresentação do produto que irão influenciar o consumidor (TOLEDO et al., 2000). Spiegel et al. (2003) citam que na indústria de alimentos existe um grande número de sistemas de garantia da qualidade disponíveis como BPF (Boas Práticas de Fabricação), APPCC (Análise de Perigos e Pontos Críticos de Controle), ISO (International Organization for Standardization) e o padrão técnico internacional do 
BRC (British Retail Consortium). Esses sistemas e suas combinações são aplicados para garantir a qualidade dos produtos alimentícios (SPIEGEL et al., 2003). Luning et al. (2002a apud SPIEGEL et al., 2003, p. 424) citam que os produtores de alimentos têm que decidir qual sistema de garantia da qualidade é mais adequado à sua situação específica, e como esse sistema deveria ser implementado. Especialmente características específicas da produção agroalimentar.

Spiegel et al. (2003) informam a respeito das diferenças entre os diversos sistemas da qualidade, conforme apresentado na Tabela I.

Tabela I. Diferenças entre sistemas de garantia da qualidade e TQM

\begin{tabular}{|c|c|c|c|c|c|c|}
\hline $\begin{array}{c}\text { Ferramentas } \\
\end{array}$ & BPF & APPCC & ISO 9001-3:1994 & BRC & ISO 9001:2000 & TQM \\
\hline $\begin{array}{l}\text { Características do sistema de qualidade } \\
\text { Estrutura organizacional } \\
\text { Responsabilidades } \\
\text { Processos } \\
\text { Procedimentos } \\
\text { Recursos }\end{array}$ & $\begin{array}{l}X \\
X\end{array}$ & X & $\begin{array}{l}X \\
X \\
X\end{array}$ & $\begin{array}{l}X \\
X \\
X \\
X \\
X\end{array}$ & $\begin{array}{l}X \\
X \\
X \\
X\end{array}$ & $\begin{array}{l}X \\
X \\
X \\
X \\
X\end{array}$ \\
\hline $\begin{array}{l}\text { Resultado } \\
\text { Segurança alimentar } \\
\text { Qualidade do produto } \\
\text { Qualidade da organização } \\
\text { Qualidade total } \\
\end{array}$ & $\begin{array}{l}X \\
X\end{array}$ & $\begin{array}{l}X \\
X\end{array}$ & $\begin{array}{l}X \\
X\end{array}$ & $\begin{array}{l}X \\
X \\
X\end{array}$ & $\begin{array}{l}X \\
X\end{array}$ & $\begin{array}{l}X \\
X \\
X \\
X\end{array}$ \\
\hline $\begin{array}{l}\text { Perspectiva } \\
\text { Tecnologia } \\
\text { Gestão } \\
\end{array}$ & X & $X$ & $\mathrm{X}$ & $\begin{array}{l}X \\
X\end{array}$ & $\mathrm{X}$ & $\mathrm{X}$ \\
\hline $\begin{array}{l}\text { Extensão } \\
\text { Mais detalhado }\end{array}$ & $\mathrm{X}$ & X & $\mathrm{X}$ & & $\mathrm{X}$ & \\
\hline $\begin{array}{l}\text { Requisitos } \\
\text { Legislação } \\
\text { Voluntário } \\
\end{array}$ & $\mathrm{X}$ & $\mathrm{X}$ & $\mathrm{X}$ & $\mathrm{X}$ & $\mathrm{X}$ & $\mathrm{X}$ \\
\hline $\begin{array}{l}\text { Gestão da qualidade } \\
\text { Controle da qualidade } \\
\text { Garantia da qualidade } \\
\text { Melhoria da qualidade } \\
\end{array}$ & $\mathrm{X}$ & $\begin{array}{l}\mathrm{X} \\
\mathrm{X}\end{array}$ & $\begin{array}{l}X \\
X\end{array}$ & $\begin{array}{l}X \\
X\end{array}$ & $\begin{array}{l}X \\
X \\
X\end{array}$ & $\begin{array}{l}X \\
X \\
X\end{array}$ \\
\hline $\begin{array}{l}\text { Método } \\
\text { Plano de implementação } \\
\text { Lista de verificação (Checklist) } \\
\text { Normas } \\
\text { Prêmios/auto-avaliação }\end{array}$ & $\mathrm{X}$ & $\mathrm{X}$ & $\mathrm{X}$ & $X$ & $X$ & $X$ \\
\hline $\begin{array}{l}\text { Sugestões para implementação } \\
\text { Descritivo } \\
\text { Normativo }\end{array}$ & $\mathrm{X}$ & $X$ & $\mathrm{X}$ & $\mathrm{X}$ & $\mathrm{X}$ & $X$ \\
\hline
\end{tabular}

Fonte: Traduzido de Spiegel et al. (2003, p. 426)

aspectos tecnológicos. É importante destacar uma diferença entre a Tabela i e a 
legislação brasileira no que tange às BPF. Na legislação brasileira BPF é uma exigência, o que a leva a ter uma sugestão normativa para implementação, diferentemente do que está exposto na Tabela I. Entretanto, apesar das BPF e do método APPCC estarem estabelecidos na legislação brasileira por meio de leis, decretos e portarias, sua aplicação é quase inexistente, o que leva a existirem problemas nos produtos brasileiros que comprometem sua qualidade passando estes a apresentarem um risco à saúde humana (BRANDIMARTI, I999).

Ao analisar o sistema agroindustrial do leite, Novo (2OOI) cita que o atraso tecnológico está presente em toda a cadeia e cita como carências do setor a produção estacional, o leite de baixa qualidade, o grande consumo de leite oriundo do mercado informal, pastos ruins em solos de baixa fertilidade, o encarecimento e escassez de mãode-obra, falta de alimento volumoso para a seca, custo de produção alto, preço do leite baixo, doenças e parasitas, dificuldades de financiamento e coleta de leite em regiões distantes.

Este atraso tecnológico se reflete também quando se analisa os sistemas de gestão da qualidade inerentes aos laticínios. Queiroz e Machado (2004, p. 8), ao analisarem a situação de uma cooperativa do estado de São Paulo, declaram:

Percebe-se que a abordagem de processos para atingir o controle de forma eficaz e eficiente e resultado em melhoria do desempenho não é empregada. Não há a definição de um manual da qualidade para que os envolvidos na produção (funcionários) sejam capazes de compreender as inter-relações e importância de cada processo no resultado final.

Os autores ainda citam:

As ações que são implementadas emanam da necessidade de controles motivados pela perecibilidade do produto e pela exigência das normas legais, ou seja, do atendimento às normas estabelecidas pelo SIF (Serviço de Inspeção Federal). Tal órgão possui um escritório nas próprias instalações do laticínio, sendo identificado como forte motivador dos procedimentos de busca pela qualidade dos produtos (QUEIROZ; MACHADO, 2004, p. 8).

Toledo et al. (2000) encontraram resultados que vão ao encontro dos resultados encontrados por Queiroz e Machado (2004). Os autores constataram que a gestão da qualidade nas seis empresas de laticínios, por eles pesquisadas, limitava-se às estruturas e práticas mínimas para o cumprimento das especificações controladas pelos organismos de inspeção governamentais. Tal situação evidenciava-se no fato de as empresas terem 
procedimentos de controle praticamente idênticos, fundamentados nessas normas e sem demonstrar interesse em adotar práticas mais elaboradas de gestão. Outro fato apontado pelos autores é que na própria visão de qualidade do produto a preocupação das empresas recaía sobre o fator custo, sendo que na opinião de representantes de três das empresas pesquisadas a satisfação do consumidor estava fortemente associada a um produto de preço inferior. Toledo et al. (2000) ainda reconhecem que os problemas relacionados com o abastecimento e a qualidade da matéria-prima e os relacionados com a estrutura organizacional e com o modelo de gestão representam os maiores entraves a uma evolução em termos de gestão da qualidade das empresas.

Para tentar promover melhorias na qualidade da matéria-prima oferecida aos laticínios a legislação brasileira tem estabelecido padrões mais rigorosos. Por meio da Instrução Normativa $n^{\circ} 5^{I}$ (BRASIL, 2002) ficou estabelecido a refrigeração do leite na fonte de produção. A granelização melhorou a qualidade do leite oferecido às indústrias, porém, as condições de higiene, manejo e transporte ainda são precárias, o que mantém as contagens de micro-organismos em desacordo com os padrões estabelecidos. Esta elevada contagem de micro-organismos, principalmente os psicrotróficos, reduz significativamente o rendimento da produção de queijos (CARDOSO, 2006, BARBOSA et al., 2009).

\section{Metodologia}

Para a elaboração do presente trabalho partiu-se da coleta do leite de um tanque de expansão que atende a uma fábrica produtora de queijos localizada no Município de Rio Pomba/MG. Foram coletados, em três repetições, 45 litros de leite cru diretamente do tanque de expansão mencionado previamente. Posteriormente, as amostras foram refrigeradas a $7^{\circ} \mathrm{C}$, que é a temperatura comumente utilizada para estocagem de leite cru, e os queijos Minas Padrão e Minas Frescal foram produzidos a partir de exatamente Io litros de leite, nos tempos o, 24, 48 e $7^{2}$ horas de incubação a $7^{\circ} \mathrm{C}$. As contagens microbiológicas (micro-organismos mesófilos aeróbios e psicrotróficos) foram realizadas antes de cada produção com o intuito de se verificar a influência da contagem de microorganismos no rendimento, usando-se, para tanto, a análise de regressão. As análises físico-químicas do leite para cada produção e dos queijos também foram realizadas com o 
intuito de se calcular o rendimento técnico ajustado. O rendimento técnico ajustado foi obtido a partir da correção da umidade para $49 \%$ no caso do queijo minas padrão e para $5^{8 \%}$ no caso do queijo minas frescal de acordo com a equação: V(IOO - Up)/P x ST, sendo (V) o volume de leite em litros, (Up) o percentual de umidade pretendida, (P) quilos de queijos produzidos e (ST) o teor de sólidos totais do queijo (FURTADO, 2005). Esse parâmetro foi considerado por levar em consideração as diferenças entre a composição físico-química dos queijos, possibilitando a comparação entre produtos com composição diferente.

Para o levantamento das perdas econômicas, fez-se simulações considerando produções de queijos com 2000 litros de leite diários para os dois tipos de queijos e valores de preços de venda equivalentes às médias dos preços de venda mensais no mercado atacadista, considerando um período de outubro de 2 OIO a setembro de $2 \mathrm{OII}$ (IEA, 2OII).

\section{Resultados e Discussão}

Os resultados das análises físico-químicas e microbiológicas do leite utilizado para a fabricação dos queijos Minas Padrão e Minas Frescal são apresentados na Tabelas 2 e 3 respectivamente.

Tabela 2. Resultados Médios das Análises Físico-químicas e Microbiológicas do Leite Utilizado para a Produção do Queijo Minas Padrão

\begin{tabular}{c|c|c|c}
\hline $\begin{array}{c}\text { Tempo } \\
\text { (Hora) }\end{array}$ & $\begin{array}{c}\text { Sólidos Totais } \\
(\%)\end{array}$ & $\begin{array}{c}\text { Mesófilos } \\
\left(\text { UFC.mL }^{-1}\right)\end{array}$ & $\begin{array}{c}\text { Psicrotróficos } \\
\left(\text { UFC.mL }^{-1}\right)\end{array}$ \\
\hline 0 & 12,85 & $9,2 \times 10^{5}$ & $1,0 \times 10^{6}$ \\
\hline 24 & 12,67 & $1,4 \times 10^{6}$ & $1,6 \times 10^{6}$ \\
\hline 48 & 12,28 & $3,9 \times 10^{6}$ & $1,9 \times 10^{6}$ \\
\hline 72 & 12,11 & $1,1 \times 10^{7}$ & $5,2 \times 10^{6}$ \\
\hline
\end{tabular}

Fonte: Dados da pesquisa, 2OII. 
Tabela 3. Resultados Médios das Análises Físico-químicas e Microbiológicas do Leite Utilizado para a Produção do Queijo Minas Frescal

\begin{tabular}{|c|c|c|c|}
\hline $\begin{array}{l}\text { Tempo } \\
\text { (Hora) } \\
\end{array}$ & \begin{tabular}{|c|} 
Sólidos Totais \\
$(\%)$ \\
\end{tabular} & $\begin{array}{c}\text { Mesófilos } \\
\left(\mathrm{UFC}_{\mathrm{mL}} \mathrm{mL}^{-1}\right) \\
\end{array}$ & 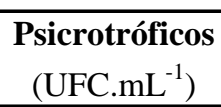 \\
\hline 0 & 13,31 & $1,9 \times 10^{4}$ & $6,2 \times 10^{3}$ \\
\hline 24 & 13,15 & $7,4 \times 10^{4}$ & $3,4 \times 10^{4}$ \\
\hline 48 & 12,74 & $6,3 \times 10^{4}$ & $8,4 \times 10^{4}$ \\
\hline 72 & 12,66 & $1,0 \times 10^{5}$ & $9,9 \times 10^{4}$ \\
\hline
\end{tabular}

Fonte: Dados da pesquisa, 2OII.

Os resultados das análises físico-químicas dos queijos Minas Padrão e Minas Frescal e os seus respectivos rendimentos técnico ajustado são apresentados nas Tabelas 4,5 e 6 .

Tabela 4. Média da composição do Queijo Minas Padrão

\begin{tabular}{c|c|c}
\hline $\begin{array}{c}\text { Tempo } \\
\text { (Hora) }\end{array}$ & $\begin{array}{c}\text { EST } \\
(\%)\end{array}$ & $\begin{array}{c}\text { Umidade } \\
(\%)\end{array}$ \\
\hline 0 & 50,9 & 49,1 \\
\hline 24 & 49,8 & 50,3 \\
\hline 48 & 48,6 & 51,4 \\
\hline 72 & 44,2 & 55,2 \\
\hline
\end{tabular}

Fonte: Dados da pesquisa, 20 II.

Tabela 5. Média da Composição do Queijo Minas Frescal

\begin{tabular}{c|c|c}
\hline $\begin{array}{c}\text { Tempo } \\
\text { (Hora) }\end{array}$ & $\begin{array}{c}\text { EST } \\
(\%)\end{array}$ & $\begin{array}{c}\text { Umidade } \\
(\%)\end{array}$ \\
\hline 0 & 42,6 & 57,4 \\
\hline 24 & 42,5 & 57,5 \\
\hline 48 & 41,2 & 58,8 \\
\hline 72 & 41,3 & 58,7 \\
\hline
\end{tabular}

Fonte: Dados da pesquisa, 20 II.

Tabela 6. Rendimento Técnico Ajustado (L de leite/ kg de queijo)

\begin{tabular}{c|c|c|c|c}
\hline $\begin{array}{c}\text { Tempo } \\
(\text { Hora) }\end{array}$ & $\begin{array}{c}\text { Minas } \\
\text { Padrão }\end{array}$ & $\begin{array}{c}\text { Perda } \\
(\boldsymbol{\%})\end{array}$ & $\begin{array}{c}\text { Minas } \\
\text { Frescal }\end{array}$ & $\begin{array}{c}\text { Perda } \\
(\boldsymbol{\%})\end{array}$ \\
\hline 0 & 9,29 & 0,00 & 6,00 & 0,00 \\
\hline 24 & 9,44 & 1,61 & 5,99 & 0,00 \\
\hline 48 & 9,93 & 6,89 & 6,64 & 10,67 \\
\hline 72 & 11,10 & 19,48 & 6,89 & 14,83 \\
\hline
\end{tabular}

Fonte: Dados da pesquisa, $20 I I$. 
Ao se realizar a análise de regressão, tem-se que o rendimento técnico ajustado, tanto para o queijo Minas Padrão quanto para o queijo Minas Frescal, foi significativamente afetado $(\mathrm{p}<\mathrm{O}, \mathrm{O} 5)$ pelo tempo de armazenamento em decorrência da contagem bacteriana encontrada. O R2 encontrado para o queijo Minas Padrão e para o queijo Minas Frescal foram, respectivamente, o,8677 e o,884I, valores estes bastante significativos (HAIR JR. et al., 2007). A Tabela 6 mostra a perda percentual de rendimento comparando-se as produções com o "Tempo o hora”, ou seja, quando os queijos foram produzidos imediatamente após a coleta do leite. Percebe-se uma perda acentuada de rendimento, em ambos os queijos, principalmente a partir do segundo dia de estocagem (Tempo 48 horas) a $7^{\circ} \mathrm{C}$. Para o queijo Minas Padrão, a perda alcançou I9,48\% enquanto que para o Minas Frescal alcançou I $4,83 \%$ ao final do período analisado. Estes resultados reforçam a necessidade de controle da qualidade microbiológica do produto, uma vez que o leite utilizado na produção do queijo Minas Padrão possuía maiores contagens de micro-organismos mesófilos aeróbios e psicrotróficos que podem produzir enzimas hidrolíticas que atuam sobre os constituintes do leite como gordura e proteína, culminando com a perda de sólidos no soro durante o processamento.

Para a análise do impacto econômico, adotou-se a média aritmética do preço dos produtos nos últimos doze meses (Tabela 7). Nas tabelas 8 e 9 são apresentadas as simulações de perda para os queijos Minas Padrão e Minas Frescal, respectivamente, adotando-se um processamento diário de 2000 litros de leite para cada produto. 
Tabela 7. Preços Médios Mensais de Venda no Mercado Atacadista

\begin{tabular}{l|c|c}
\hline \multirow{2}{*}{ Período } & \multicolumn{2}{|c}{ Preços em R\$ } \\
\cline { 2 - 3 } & Minas Padrão & Minas Frescal \\
\hline Outubro 2010 & 13,55 & 10,01 \\
\hline Novembro 2010 & 14,46 & 10,86 \\
\hline Dezembro 2010 & 15,04 & 10,75 \\
\hline Janeiro 2011 & 15,45 & 9,41 \\
\hline Fevereiro 2011 & 15,28 & 9,59 \\
\hline Março 2011 & 14,37 & 9,29 \\
\hline Abril 2011 & 15,00 & 9,43 \\
\hline Maio 2011 & 15,61 & 9,87 \\
\hline Junho 2011 & 15,71 & 9,67 \\
\hline Julho 2011 & 16,02 & 10,02 \\
\hline Agosto 2011 & 15,44 & 10,02 \\
\hline Setembro 2011 & 15,82 & 10,43 \\
\hline \multicolumn{1}{|c|}{ MÉDIA: } & $\mathbf{1 5 , 1 5}$ & $\mathbf{9 , 9 5}$ \\
\hline
\end{tabular}

Fonte: IEA, 2OII.

Tabela 8. Simulação para perdas financeiras com o Queijo Minas Padrão: 2ooo L de leite/dia

\begin{tabular}{r|c|c|r|r|r}
\hline $\begin{array}{c}\text { Rendimento } \\
(\mathbf{L} / \mathbf{k g})\end{array}$ & $\begin{array}{c}\text { Produto } \\
(\mathbf{k g})\end{array}$ & $\begin{array}{c}\text { Preço } \\
(\mathbf{R} \mathbf{})\end{array}$ & $\begin{array}{r}\text { Perdas Diárias } \\
(\mathbf{R} \mathbf{})\end{array}$ & $\begin{array}{r}\text { Perdas Mensais } \\
(\mathbf{R} \mathbf{)}\end{array}$ & \multicolumn{1}{c}{$\begin{array}{c}\text { Perdas Anuais } \\
(\mathbf{R} \mathbf{})\end{array}$} \\
\hline 9,29 & 215,29 & 15,15 & 0,00 & 0,00 & 0,00 \\
\hline 9,44 & 211,86 & 15,15 & 51,83 & 1554,77 & 18657,30 \\
\hline 9,93 & 201,41 & 15,15 & 210,21 & 6306,36 & 75676,34 \\
\hline 11,10 & 180,18 & 15,15 & 531,84 & 15955,26 & 191463,07 \\
\hline
\end{tabular}

Fonte: Dados da pesquisa, 20II.

Tabela 9. Simulação para perdas financeiras com o Queijo Minas Frescal: $2000 \mathrm{~L}$ de leite/dia

\begin{tabular}{r|r|r|r|r|r}
\hline $\begin{array}{c}\text { Rendimento } \\
(\mathbf{L} / \mathbf{k g})\end{array}$ & $\begin{array}{c}\text { Produto } \\
(\mathbf{k g})\end{array}$ & $\begin{array}{c}\text { Preço } \\
(\mathbf{R} \mathbf{})\end{array}$ & $\begin{array}{r}\text { Perdas Diárias } \\
(\mathbf{R} \mathbf{})\end{array}$ & $\begin{array}{c}\text { Perdas Mensais } \\
(\mathbf{R} \mathbf{})\end{array}$ & $\begin{array}{c}\text { Perdas Anuais } \\
(\mathbf{R} \mathbf{)}\end{array}$ \\
\hline 6,00 & 333,33 & 9,95 & 0,00 & 0,00 & 0,00 \\
\hline 5,99 & 333,89 & 9,95 & 0,00 & 0,00 & 0,00 \\
\hline 6,64 & 301,20 & 9,95 & 319,68 & 9590,36 & 115084,34 \\
\hline 6,89 & 290,28 & 9,95 & 428,42 & 12852,69 & 154232,22 \\
\hline
\end{tabular}

Fonte: Dados da pesquisa, $20 I I$.

Como pode-se observar nas tabelas 8 e 9, as perdas financeiras são significativas, principalmente quando se analisa que a realidade para o nível de produção simulada é condizente com a realidade de micro e pequenas empresas brasileiras e em especial da região à qual pertence a indústria analisada. Somando-se as perdas anuais para os dois tipos de produtos tem-se $\mathrm{R} \$ 345.695,29$, quando se trata de um cenário onde o leite 
destinado à produção foi estocado por $7^{2}$ horas. Essa cifra pode ser determinante para a permanência de uma pequena empresa no mercado.

\section{Conclusão}

Apesar da incontestável importância do setor agroalimentar para o país, o número de trabalhos que tratam da gestão da qualidade em tal setor é pouco expressivo (TOLEDO et al., 200O). Tal situação é reflexo da pouca importância dada ao tema pelos próprios empresários, como apresentado por Toledo et al. (2000) e Queiroz e Machado (2004), que veem os sistemas de garantia da qualidade mais como um mecanismo de atendimento da legislação do que como uma forma para atingir o melhoramento contínuo do produto. As empresas e empresários do setor de alimentos e em específico de lácteos precisam se conscientizar da importância de se ter a gestão da qualidade como uma filosofia de gestão, proporcionando mudanças profundas na organização, mais do que como uma ferramenta de gestão.

Como afirma Cordeiro (2004), a gestão da qualidade como panaceia de gestão nas empresas se encontra em seu "leito de morte", porém sua imensa contribuição não pode ser descartada. No presente estudo torna-se evidente que a adoção de uma gestão da qualidade integrada pode influenciar positivamente o retorno financeiro, ao reduzir as perdas oriundas pela falta de controle adequado a fim de limitar a contaminação do leite, dentre outros pontos importantes na tecnologia de fabricação de queijos.

Não se pode negar que há um custo envolvido para a implantação de um sistema de gestão da qualidade. Porém, ao se analisar a cadeia do leite, tem-se algumas técnicas profiláticas básicas, como o cuidado com a higiene e limpeza, que são significativas para a melhoria da matéria-prima (GUERREIRO et al., 2005). Como proposta para futuros estudos tem-se a análise da relação custo/benefício da implementação de um sistema de gestão da qualidade em indústrias de laticínios.

Por fim, considerando-se as perdas nos ensaios realizados, conclui-se que a implementação da gestão da qualidade na indústria queijeira analisada melhoraria seu desempenho operacional e econômico. 


\section{Referências}

ARNOLD, B.; GÖB, R. Sample Method and Quality Control. In: VIERTL, R. Probability and Statistics - Vol.3. In: Encyclopedia of Life Support Systems (EOLSS), Developed under the Auspices of the UNESCO. Oxford : Eolss Publishers, 2005. Disponível em: $<$ http://www.eolss.net $>$. Acesso em: OI/IO/2OII.

BARBOSA, J. B.; TALMA, S. V.; BATISTA, C. S.; MARTINS, M. L.; PINTO, C. L. O. Avaliação de rendimento da produção dos queijos minas frescal, minas padrão e mussarela fabricados com leite inoculado com pseudômonas fluorescens. Revista do Instituto de Laticínios Cândido Tostes, Nov/Dez, n. ${ }^{\circ} 37$ I, v.64, p. 26-33, 2009.

BRANDIMARTI, L. Comer é questão de vida ou de morte. Revista Digital Banas Qualidade, jun. I999. Disponível em: <http://www.banasqualidade.com.br>. Acesso em: oI/Io/2OII.

BRASIL. 2002. Ministério da Agricultura, Pecuária e Abastecimento. Departamento de Inspeção de Produtos de Origem Animal. Instrução Normativa ${ }^{\circ}{ }^{5}{ }^{\mathrm{I}}$ de $\mathrm{I} 8$ de setembro de 2002. Coleta de leite cru refrigerado e seu transporte a granel. Diário Oficial da União. Brasília. I72, p. 8-ı3, 20 de setembro. Seção I.

CAMPOS, V. M. C. Uso e necessidade de informação tecnológica: um diagnóstico do setor de laticínios do Estado de Minas Gerais. Perspectivas em Ciência da Informação, Belo Horizonte, v.2, n.I, p. 37-63, jan./jun., I997.

CARDOSO, R. R. Influência da microbiota psicrotrófica no rendimento de queijo minas frescal elaborado com leite estocado sob refrigeração. 2006. 57 f. Dissertação (Mestrado em Microbiologia Agrícola) - Universidade Federal de Viçosa. Viçosa, MG, 2006.

CARVALHO, G. R. A Indústria de laticínios no Brasil: passado, presente e futuro. Circular Técnica IO2. Juiz de Fora: EMBRAPA, 2 OIO.

CARVALHO, G. R.; HOTT, M. C.; OLIVEIRA, A. F. Análise espacial da produção de leite no Estado de Minas Gerais em base microrregional. In: Congresso da Sociedade Brasileira de Economia, Administração e Sociologia Rural. 45, 2007, Londrina. Anais Eletrônicos. Disponível em:

$<$ http://www.sober.org.br/palestra/6/733.pdf>. Acesso em: OI/IO/2OII.

CERQUEIRA, J. P. Sistemas de gestão integrados: ISO 900I, ISSO ı 40o, OHSAS I8ooI, AS 8ooo, NBR ı6oor, conceitos e aplicações. Rio de Janeiro: Qualitymark, 2007.

CORDEIRO, J. V. B. M. Reflexões sobre a Gestão da Qualidade Total: fim de mais um modismo ou incorporação do conceito por meio de novas ferramentas de gestão? Revista da FAE, Curitiba, v.7, n.I, p. 19-33, jan./jun., 2004.

CROSBY, P. B. Quality is free. New York: New American Library, I979.

DEMING, W. E. Qualidade: A Revolução da Administração. Rio de Janeiro: Marques Saraiva, I99O.

ETZIONI, A. Organizações Complexas. São Paulo: Atlas, I98ı.

FURTADO, M. M. Principais problemas em queijos: causa e prevenção. São Paulo: Fonte de Comunicações e Editora, 2005 .

GARVIN, D. A. Gerenciando a Qualidade: a visão estratégica e competitiva. Rio de Janeiro: Qualitymark, 2002. 
GUERREIRO, P. K.; MACHADO, M. R. F.; BRAGA, G. C.; GASPARINO, E.; FRANZENER, A. S. M. Qualidade microbiológica de leite em função de técnicas profiláticas no manejo de produção. Ciência e Agrotecnologia, Lavras, v.29, n.I, p. 2I6-222, jan./ fev., 2005.

HAIR JR., J. F.; ANDERSON, R. E.; TATHAN, R. L.; BLACK, W. C. Análise multivariada de dados. 5.ed. São Paulo. Bookman: 20O7.

ISHIKAWA, K. How to operate QC circles activities. Tokio: JUSE, I985.

INSTITUTO DE ECONOMIA AGRÍCOLA - IEA. Preços Médios Mensais de Venda no Mercado Atacadista. Disponível em: $\langle$ http://ciagri.iea.sp.gov.br/bancoiea/Precos_Medios.aspx?cod_sis=3 $>$. Acesso em: 02/IO/2OII.

JURAN, J. M.; GRYNA JR., F. M. Quality planning and analysis. New York: McGraw-Hill, I980.

LONGO, R. M. J. Gestão da Qualidade: Evolução Histórica, Conceitos Básicos e Aplicação na Educação. Texto para Discussão, Brasília, n.397, jan.1996.

MILINSKI, C. C.; GUEDINE, P. S. M.; VENTURA, C. A. A. O Sistema Agroindustrial do Leite no Brasil: Uma Análise Sistêmica. In: Congresso Brasileiro de Sistemas. 4, 2008, Franca. Anais Eletrônicos. Disponível em: <http://www.facef.br/quartocbs/artigos/C/C_I5I.pdf > . Acesso em: $\mathrm{OI} / \mathrm{IO} / 2 \mathrm{OII}$.

NOVO, A. L. M. Avaliação de programas privados de assistência técnica no setor leiteiro: um estudo de caso do departamento de assistência ao produtor Parmalat. São Carlos, 20OI. Dissertação (Mestrado em Engenharia de Produção) - DEP/UFSCar.

QUEIROZ, T. R.; MACHADO, M. D. Análise da gestão da qualidade em empresas agroindustriais o caso da Colascric. In: Simpósio de Engenharia de Produção. II, 2004, Bauru. Anais Eletrônicos. Disponível em: $<$ http://www.simpep.feb.unesp.br/anais/anais_II/anais_II.php >. Acesso em: OI/IO/2OII.

SPIEGEL, M. V.; LUNING, P. A.; ZIGGERS, G. W.; JONGEN, W. M. F. Towards a conceptual model to measure effectiveness of food quality systems. Trends in Food Science \& Technology, n.I4, p. 424-43I, 2003 .

TOLEDO, J. C.; BATALHA, M. O.; AMARAL, D. C. Qualidade na indústria agroalimentar: situação atual e perspectivas. Revista de Administração de Empresas, São Paulo, v.4O, n.2, p. 9O-IOI, abr./jun., 2000 . 